\title{
DIPLEGIA FACIAL TRAUMATICA
}

\author{
J. Fortes-Rego *
}

A paralisia facial periférica unilateral é condição freqüente e, embora a forma considerada idiopática tenha predomínio estatísitco", numerosos são os fatores implicados na sua etiologia, cabendo mencionar, entre estes, os traumatismos cranianos, cuja importância não parece fácil determinar com precisão, em face dos dados divergentes oferecidos nas diversas casuísticas relatadas. Assim, entre as 19 causas distintas de paralisia facial encontradas por May \& Lucente ${ }^{19}$, em 28 dos seus 160 pacientes, não há referência a traumatismo, no que coincide com a série de 446 casos de Adour \& Wingerd ${ }^{1}$, onde 245 apresentaram uma outra afecção aguda ou crônica. Muitas outras publicações similares poderiam ser facilmente evocadas, porém procuraremos dar maior ênfase àquelas em que o traumatismo craniano é mencionado. Eis alguns exemplos: 7 em $251^{13}, 2$ em $79^{2}, 119$ em $735^{5}, 23 \mathrm{em}$ $340^{12}$, 1 em $483^{29}, 72$ em $606^{14}$, 1 em $80^{30}$, 15 em $146^{33}$ e 2 em $61^{18}$, referindo-se esta última a crianças menores de 14 anos. Outros autores simplesmente reportam seus casos de paralisia traumática ${ }^{11,27}$.

Ponto pacífico entre os autores relaciona-se ao progressivo aumento na

freqüência de paralisias faciais traumáticas, como conseqüência do número cada vez maior de acidentes de tráfego, industrial e de aviação ${ }^{22}$. Neste particular, os números apresentados por Koike ${ }^{17}$, em Niigata, Japão, são bastante significativos: $1967-12,1968-19,1969-28$ e 1970 (janeiro a agosto) - 29 casos. Também Paunescu \& col. ${ }^{26}$, ao comunicarem um total de 33 casos de paralisia facial em crianças, num periodo de 8 anos, ressaltaram um importante aumento no número de casos de origem pós-traumática, em contraste com uma considerável redução nos decorrentes de eventos não traumáticos. Cremos oportuno destacar ainda a grande importância que se atribui aos traumatismos de face na produção de parilisia facial extratemporal 6,15. Em algumas eventualidades, situações curiosas são mencionadas em associação com paralisia facial periférica: fratura de mandíbula ${ }^{23}$, lesões traumáticas da cadeia ossicular ${ }^{25}$, tentativa mal sucedida de remoção de um corpo estranho do conduto auditivo externo ${ }^{8}$, após anestesia troncular do nervo dentário inferior acima do orifício superior do conduto dentário 7 .

E geralmente admitido que a paralisia facial periférica é causada, na maior parte dos casos de traumatismo fechado de crânio, por uma fratura do osso temporal, podendo esta ser transversa ou longitudinal. O lugar de

Departamento de Medicina Especializada, Faculdade de Ciências da Saúde, Universidade de Brasilia: * Professor-Assistente. 
sofrimento do nervo facial parece ser determinado mais pela singular disposição do osso temporal, do que por um tipo particular de traumatismo ou fratura do crânio. McHugh ${ }^{21}$, citando vários autores, afirma que o local mais comum de lesão do nervo facial, em fraturas transversas e longitudinais do osso temporal, é dentro do ouvido médio. No primeiro tipo de fratura, o nervo é frequentemente lacerado ou completamente seccionado enquanto que, nas longitudinais, é distendido, contundido, edemaciado e comprimido pelos fragmentos ósseos, porém só raramente lacerado.

Uma fratura transversa do osso temporal é usualmente o resultado de uma força aplicada às regiões occipital ou occipitomastóidea e mostra considerável variação em posição e direção. Nela, há rotura da cápsula óssea do ouvido interno, perpendicular ao grande eixo da pirâmide petrosa, e o nervo facial é mais freqüente e severamente lesado. Segundo as estatísticas de Siebenmenn (1890) e Hahn (1955), citados por Miehlke ${ }^{22}$, aproximadamente $30-50 \%$ dos pacientes que sofrem este tipo de fratura, apresentam concomitantemente paralisia facial.

As fraturas longitudinais do osso temporal, paralelas ao grande eixo da pirâmide petrosa, são muito mais comuns que as transversas. Este tipo de fratura usualmente envolve o assoalho da fossa craniana média, poupa a cápsula óssea do ouvido interno, porém freqüentemente - se não sempre lesa o ouvido médio. O nervo facial pode ser atingido na porção timpânica, distal ao gânglio geniculado ou, em raras ocasiões, na porção vertical, na mastóide. Uma fratura longitudinal é comumente devida a uma força aplicada à região temporoparietal e, segundo a maioria dos autores, tem um curso típico. Em 10 a $25 \%$ dos casos provoca paralisia facial, sendo esta de melhor prognósitco com relação às oriundas das fraturas transversas.

A seguir faremos o relato de um caso de paralisia facial bilateral e hipoacusia esquerda surgida após traumatismo cranioencefálico.

\section{OBSERVAÇÃO}

R. S. B. (Reg. 125480), com 26 anos de idade, sexo masculino, moreno, casado, foi admitido no Hospital Universitário de Brasilia em 24-10-1974, relatando que, 12 dias antes, caira de um caminhão em movimento, batendo com a cabeça de encontro ao solo, sendo atingido diretamente o lado direito. Perdeu a consciência por um lapso de duas horas e, ao recuperá-la, referia cefaléia e zumbidos, apresentando, ademais, otorragia bilateral. Ao deambular, no $4 .^{\circ}$ dia, sentiu vertigens e exibia uma marcha insegura, com tendência a cair para os lados. O exame neurológico pôs de manifesto uma acentuada limitação funcional da musculatura facial nos dois territórios, bilateralmente, abolição do reflexo naso-palpebral dos dois lados e diminuição da acuidade auditiva à esquerda, sem outras anormalidades. O deficit motor predominava à esquerda. O estudo radiológico do crânio evidenciou uma fratura longitudinal, de $10 \mathrm{~cm}$ de comprimento, no osso occipital, além de uma fratura no rochedo esquerdo (Fig. 1). 


\section{COMENTARIOS}

A diplegia facial secundária a traumatismo craniano é rara ${ }^{10,16,20,28}$. McHugh ${ }^{21}$ estabelece que a paralisia facial em fraturas longitudinais do
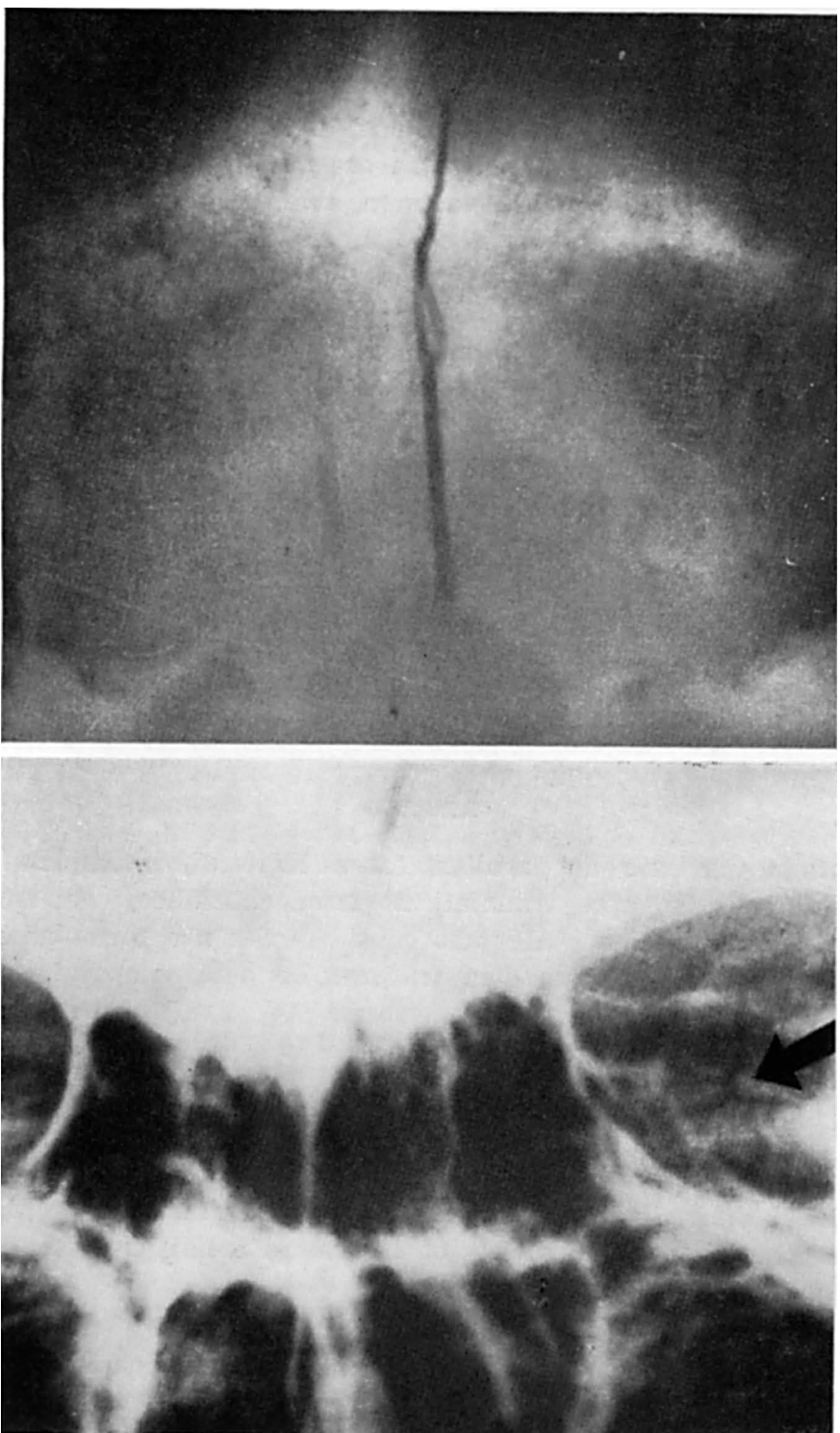

Fig. 1 - Caso R. S. B. Radiografias do crânio: na parte superior, fratura longitudinal mediana no osso occipital; na parte inferior (seta), traco (le fratura em $Y$ no rochedo esquerdo. 
osso temporal pode ser uni ou bilateral, parcial ou completa, imediata ou tardia. A paralisia imediata, geralmente completa, é devida à interrupção do nervo no aqueduto de Falópio. Nos casos bilaterais, a paralisia pode ser imediata em ambos os lados, tardia nos dois, ou imediata em um lado e tardia no outro, ou estar presente quando a fratura é demonstrada pelas radiografias só em um lado. O surgimento tardio da paralisia traumática é atribuído a edema ou hematoma no canal facial.

Embora reconheça-se uma origem intratemporal para $90 \%^{3}$ ou mesmo $95 \%{ }^{4}$ das paralisias faciais periféricas, a associação de lesão deste osso com acometimento do mencionado nervo nem sempre é clara. Assim, Tos ${ }^{31}$, revendo 500 casos da doença de Hand-Schuler-Christian registrados na literatura, encontrou, em 284, lesões do osso temporal, sendo estas bilaterais 144 vezes e considerou surprendente o fato de somente 8 terem apresentado paralisia facial intratemporal, bilateral em apenas um caso.

Nosso paciente apresentou indícios de fratura de fossa média (confirmada radiologicamente à esquerda), paralisia facial periférica bilateral, incompleta, provavelmente imediata e hipoacusia esquerda. Aliás, é notória a dificuldade em evidenciar uma fratura de base de crânio, mesmo com a utilização de técnicas especiais ${ }^{32}$. Por outro lado, destaca Miller ${ }^{24}$ que a paralisia facial secundária a traumatismo é muito mais comum na vigência de perda sangüinea ou liquórica pelo ouvido, em cuja eventualidade costuma associar-se surdez por lesão do ouvido médio. Um aspecto até certo ponto particular do presente caso refere-se à extensa fratura mediana do occipital, exatamente na área de maior consistência do osso.

\section{RESUMO}

E relatado um caso de paralisia facial bilateral, incompleta, associada a hipoacusia esquerda, após traumatismo cranioencefálico, com fraturas evidenciadas radiologicamente. Algumas considerações são formuladas tentando relacionar ditas manifestaçōes com fraturas do osso temporal.

\section{SUMMARY}

Traumatic facial diplegia: a case report

A case of traumatic facial diplegia with left partial loss of hearing following head injury is reported. X-rays showed fractures on the occipital and left temporal bones. A review of traumatic facial paralysis is made.

\section{REFERENCIAS}

1. ADOUR, K. K. \& WINGERD, J. - Idiopathic facial paralysis (Bell'palsy): factors affecting severity and outcome in 446 patients. Neurology (Minneapolis) $24: 1112,1974$.

2. AMINOFF, M. J. \& MILlER, A. L. - The prevalence of diabetes mellitus in patients with Bell's palsy. Acta Neurol. Scandinavica 48:381, 1972.

3. BROOKLER, K. H.; PULEC, J. C. \& HALlbERG, O. E. - Congenital cholesteatoma of the temporal bone. Arch. Otolaryng. 90:449, 1969.

4. CAWTHORNE, T. — Intratemporal facial palsy. Arch. Otolaryng. 90:789, 1969. 
5. CAWTHORNE, T. \& WILSON, T. - Indications for intratemporal facial nerve surgery. Arch. Otolaryng. 78:429, 1963.

6. ENEROTH, C. M. — Facial nerve paralysis. Arch. Otolaryng. 95:300, 1972.

7. FERNANDEZ, E. G. - Paralisis facial y sus causas. An. Esp. Odontoestomat. $28: 419,1969$.

8. FERNANDEZ-BLASINI, N. W BUNKER, R. J. - Traumatic facial palsy. Arch. Otolaryng. 90:137, 1969.

9. FORTES-REGO, J. - Etiologia da paralisia facial periférica. Arq. Neuro-Psiquiat. (São Paulo) 32:131, 1974.

10. GAILlARD, J.; DUMOLARD, P. \& CETRE, J. - Diplégie faciale post-traumatique. J. Fr. Otolaryngol. 19:817, 1970.

11. GRAVES, T. A. \& TABB, H. G. - Management of traumatic facial nerve paralysis. Excerpta Medica 25:577, 1972 (resumo).

12. GROVES, J. - Facial palsies: selection of cases for treatment. Proc. Roy. Soc. Med. 66:545, 1973.

13. HAUSER, W. A.; KARNES, W. E.; ANNIS, J. \& KURLAND, L. T. - Incidence and prognosis of Bell's palsy in the population of Rochester, Minnesota, Mayo Clinjc Proc. 46:258, 1971.

14. JONGKEES, L. B. W. - On peripheral facial nerve paralysis. Arch. Otolaryng. 95:317, 1972.

15. KITAMURA, T.; TOGAWA, K.; TSUKAMOTO, K. \& NAITO, J. - Extratemporal facial nerve surgery. Arch. Otolaryng. 95:369, 1972.

16. KOBAYASHI, T. - Bilateral facial palsy. Excerpta Medica 31:667, 1974 (resumo).

17. KOIKE, Y. - Facial palsies due to skull trauma. Arch. Otolaryng. 95:434, 1972 .

18. MANNING, J. J. \& ADOUR, K. K. - Facial paralysis in children. Diagnosis and treatment. Pediatrics 49:102, 1972.

19. MAY, M. \& LUCENTE, F. E. - Bell's palsy caused by basal cell carcinoma. JAMA 220:1596, 1972.

20. McGOVERN, F. H. - Bilateral Bell's palsy. Laryngoscope 75:1070, 1965.

21. McHUGH, H. E. - Facial paralysis in birth injury and skull fractures. Arch. Otolaryng. 78:443, 1963.

22. MIEHLKE, A. - Recognition and management of facial nerve palsies of operative and traumatic origin. Proc. Roy. Soc. Med. 66:549, 1973.

23. MILFORD, M. C. \& LOIZEAUX, A. D. - Facial paralysis secondary to mandibular fracture: report of case. Excerpta Medica 26:305, 1973 (resumo).

24. MILleR, H. - Facial paralysis. Brit. Med. J. 3:815, 1967.

25. MUNOZ BORGE, F. \& MARCO, J. - Traumatic injuries of the ossicular chain. Excerpta Medica 26:503, 1973 (resumo).

26. PAUNESCU, C.; LACRITEANU, U. \& SARAFOLEANU, D. - Considerations on peripheral facial paralysis in children. Excerpta Medica 26:186, 1973 (resumo).

27. RICHARDS, A. - Traumatic facial palsy. Proc. Roy. Soc. Med. 66:556, 1973.

28. RONTAL, E. \& SIGEL, M. E. - Bilateral facial paralysis. Laryngoscope 82: 607,1972 .

29. TAVERNER, D. - Medical management of idiopathic facial (Bell's) palsy. Proc. Roy. Soc. Med. 66:554, 1973.

30. TOMITA, H.; HAYAKAWA, W. \& HONDO, R. - Varicella-zoster virus in idiopathic facial palsy. Arch. Otolaryngology 92:365, 1972.

31. TOS, M. - Facial palsy in Hand-Schuller-Christian's disease. Arch. Otolaryng. $90: 563,1969$.

32. WRIGHT, J. W. \& TAYLOR, C. E. - Facial nerve abnormalities revealed by polytomography. Arch. Otolaryng. 95:426, 1972.

33. YANAGIHARA, N. \& KISHIMOTO, M. - Electrodiagnosis in facial palsy. Arch. Otolaryng. 95:376, 1972.

Departamento de Medicina Especializada - Faculdade de Ciências aa Saúde - Universidade de Brasilia - 70000 Brasilia, DF - Brasil. 